\title{
COMPOSIÇÃO FLORÍSTICA DO ESTRATO ARBÓREO DE FLORESTA ATLÂNTICA INTERIORANA EM ARAPONGA - MINAS GERAIS ${ }^{1}$
}

\author{
Michellia Pereira Soares², Amilcar Walter Saporetti Junior ${ }^{3}$, João Augusto Alves Meira Neto ${ }^{4}$, Alexandre \\ Francisco da Silva ${ }^{4}$ e Agostinho Lopes de Souza
}

\begin{abstract}
RESUMO - Os objetivos deste trabalho foram determinar a composição florística de um fragmento de Floresta e analisar a sua similaridade com outras áreas de Floresta Estacional Semidecidual e Floresta Ombrófila Densa, com o intuito de classificar a tipologia florestal da área de estudo. O levantamento foi realizado em uma

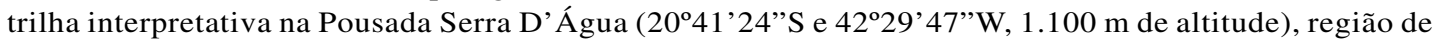
entorno do Parque Estadual da Serra do Brigadeiro (PESB), Município de Araponga, MG. A listagem florística foi obtida a partir do levantamento fitossociológico, no qual foram demarcados 150 pontos quadrantes. Foram relacionadas 147 espécies, 98 gêneros e 50 famílias. As famílias com maior número de espécies foram: Melastomataceae (14), Leguminosae (11), Myrtaceae (10), Rubiaceae (8), Annonaceae (7), Flacourtiaceae (7), Lauraceae (7) e Meliaceae (6). Os resultados da análise de agrupamento revelaram que os aspectos de proximidade geográfica e altitude são os principais responsáveis pela similaridade florística de muitas áreas. A vegetação da área de estudo pode ser classificada como Floresta Estacional Semidecidual Montana, pelo fato de a sua composição florística mostrar alta similaridade com outras áreas dessa mesma tipologia.
\end{abstract}

Palavras-chave: Composição florística, Floresta Estacional Semidecidual Montana e similaridade florística.

\section{TREE STRATUM FLORISTIC COMPOSITION OF AN INLAND ATLANTIC FOREST IN ARAPONGA - MG}

\begin{abstract}
The objective of this work was to determine the floristic composition of a forest fragment and to analyze its similarity with other areas of the Semideciduous Seasonal Forest and Dense Ombrophylous Forest, in order to classify the forest typology of this area. The survey was carried out in an interpretative trail at the Pousada Serra D'Água (20'41'24"S and 42029'47'W, $1100 \mathrm{~m}$ altitude), in the region around the Serra do Brigadeiro State Park (PESB), municipality of Araponga, MG. The floristic list was obtained from the phytosociological survey in which 150 quarter-centered-points were established. A total of 147 species, 98 genera and 50 families were found. The families with the greatest number of species were: Melastomataceae (14), Leguminosae (11), Myrtaceae (10), Rubiaceae (8), Annonaceae (7), Flacourtiaceae (7), Lauraceae (7) and Meliaceae (6). The results of the cluster analysis showed that the aspects of geographic proximity and altitude are the main factors responsible for the floristic similarity of many areas. The vegetation of the studied area can be classified as Montane Semideciduous Seasonal Forest, since its floristic composition shows a great similarity with other areas of the same typology.
\end{abstract}

Keyworks: floristic composition, Montane Semideciduous Seasonal Forest, floristic similarity.

\footnotetext{
${ }^{1}$ Recebido em 20.4.2005 e aceito para publicação em 05.04.2006.

${ }^{2}$ Bióloga. E-mail: <michellia@vicosa.ufv.br>.

${ }^{3}$ Programa de Pós-Graduação em Botânica da Universidade Federal de Viçosa, UFV.

${ }^{4}$ Departamento de Biologia Vegetal da Universidade Federal de Viçosa,UFV, 36571-000 Viçosa-MG.

${ }^{5}$ Departamento de Engenharia Florestal da Universidade Federal de Viçosa, UFV, 36571-000 Viçosa-MG.
} 


\section{INTRODUÇÃO}

O bioma Mata Atlântica atualmente é considerado um dos conjuntos mais ricos de ecossistemas em termos de diversidade biológica do Planeta (CAPOBIANCO, 2002). As formações florestais são um exemplo dessa grande diversidade. Nas Regiões Sudeste e Sul do Brasil, as Florestas Montanas são objetos de intensa pesquisa, porém são poucas as informações sobre a composição florística daquelas situadas acima de $1.000 \mathrm{~m}$ de altitude. No Sudeste brasileiro, um pouco dessa composição foi relacionada nos trabalhos realizados por MeiraNeto et al. (1989), Oliveira-Filho et al. (1994), Pedralli et al. (2000), Ribeiro (2003), Oliveira-Filho et al. (2004), França e Stehmann (2004) e Saporetti Junior (2005).

A classificação da vegetação brasileira adotada pelo IBGE para essas formações segue uma nomenclatura universal (VELOSO et al., 1991), um método direcionado ao mapeamento de áreas, embasado na precipitação, temperatura, altitude e latitude. O caráter ombrófilo e estacional é interpretado pelas correlações de pluviosidade e temperatura. Entretanto, quando se leva em consideração a extensão do território brasileiro, a grande heterogeneidade das suas paisagens, o conhecimento ainda incipiente de sua flora e as variações fisionômicas no mesmo compartimento vegetacional (TORRES et al., 1997), muitas classificações desse sistema não são claras. Para a classificação das Florestas Montanas, a primeira dificuldade foi o estabelecimento do limite altitudinal (WEBSTER, 1995), pois a variação de fisionomia e estrutura se dá a curtas distâncias (WHITMORE, 1990). Trabalhos recentes evidenciaram que fatores como solo, clima, relevo e composição florística podem auxiliar no melhor conhecimento da distribuição geográfica dessas formações (TORRES et al., 1997; OLIVEIRA-FILHO e FONTES, 2000).

A Serra do Brigadeiro, localizada em parte no Município de Araponga, Zona da Mata mineira, faz parte do complexo da Mantiqueira, que, juntamente com a Serra do Mar, detém grandes remanescentes da Mata Atlântica. As suas cotas altimétricas variam de 1.000 a $2.000 \mathrm{~m}$. A Serra apresenta condições ecológicas muito diferentes das áreas vizinhas, impostas pelo conjunto de cadeias montanhosas, os vales profundos e estreitos que condicionam a existência de um microclima peculiar - frio, de alta pluviosidade e elevada umidade relativa nos vales, com uma flora ainda pouco conhecida (COUTO e DIETZ, 1980).

R. Árvore, Viçosa-MG, v.30, n.5, p.859-870, 2006
Portanto, este trabalho teve como objetivo listar as espécies arbóreas que ocorrem em um trecho de Floresta Atlântica Interiorana na Serra do Brigadeiro e classificar a tipologia florestal da área por meio de comparação com áreas de Floresta Estacional Semidecidual e Floresta Ombrófila Densa das Regiões Sudeste e Sul do Brasil.

\section{MATERIAL E MÉTODOS}

\section{1. Área de estudo}

O presente trabalho foi realizado em área da propriedade da Pousada Serra D'Água (2041'24"S e 42²9'47'W, altitude de $1.100 \mathrm{~m}$ ), região do entorno do Parque Estadual da Serra do Brigadeiro (PESB), Município de Araponga, sudeste de Minas Gerais, Zona da Mata mineira. Nas décadas de 1950 e 70 ocorreu a extração madeireira na região para a produção de carvão, formação de pastagens e plantio de café, entretanto a área estudada foi uma das poucas resguardadas dessas ações. Atualmente, a intervenção antrópica no local acontece na forma de retirada de lenha para subsistência dos moradores próximos, pisoteio de gado e abertura de trilhas para a visita de turistas.

Segundo a classificação de Veloso et al. (1991) e levantamento florístico (RIBEIRO, 2003), a vegetação florestal existente na Serra do Brigadeiro é caracterizada como Floresta Estacional Semidecidual e Floresta Ombrófila Densa. Além das florestas, ocorrem os Campos de Altitude (CAIAFA, 2002). Parte do local estudado está adjacente a um curso d'água, apresentando dossel contínuo.

O clima da região é do tipo $\mathrm{CW}_{\mathrm{b}}$, de Köppen (tropical de altitude, com verões frescos e chuvosos) (VALVERDE, 1958). A temperatura média anual é de $18^{\circ} \mathrm{C}$, e a precipitação média anual é de cerca de $1.300 \mathrm{~mm}$ (ENGEVIX, 1995). Nos meses de inverno, que coincidem com o período seco, são registradas chuvas ocasionais conjuntamente com fortes ventos, evento denominado no local como corrupiana (observação pessoal). Os tipos de solo encontrados predominantemente são: Latossolo Vermelho-Amarelo, Latossolo VermelhoAmarelo Distrófico Húmico, Cambissolos e Neossolo Litólico (ENGEVIX, 1995; EMBRAPA, 1999).

\subsection{Composição florística}

A lista florística foi elaborada a partir de uma amostra fitossociológica, utilizando-se o método de pontoquadrante (COTTAM e CURTIS, 1956), com um total 
de 150 pontos. O critério de inclusão utilizado foi de circunferência do caule a 1,30 m do solo (CAP) superior ou igual a $15 \mathrm{~cm}$. A identificação taxonômica foi feita por meio de literatura especializada, consultas a herbários e especialistas. Para a citação dos binômios específicos, empregou-se o Index Kewensis, "software" do Royal Botanical Gardens of Kew (1993), o "site" do Missouri Botanical Garden http://www.mobot.org/w3T/search/ vast.html, (acesso em dezembro de 2004) e obras mais recentes. Os materiais férteis serão depositados no Herbário do Departamento de Biologia Vegetal da Universidade Federal de Viçosa (VIC). O sistema de classificação adotado para a elaboração da lista florística seguiu o proposto por Cronquist (1988), exceto para Leguminosae, a qual foi considerada com as três subfamílias (JOLY, 1998).

Para a classificação das pteridófitas, utilizou-se a de Fernandes (1997).

\subsection{Análise de agrupamento}

Para classificar a tipologia florestal da área, comparouse a lista florística obtida com outras 24 que incluem levantamentos em Floresta Estacional Semidecidual e Floresta Ombrófila Densa das Regiões Sudeste e Sul do Brasil (Quadro 1 e Figura 1). Para a uniformização da classificação, seguiu-se a proposta elaborada por Veloso et al. (1991). A similaridade florística entre as áreas foi verificada por meio de análise de agrupamento utilizando o índice de similaridade de SÆrensen (MUELLER-DOMBOIS e ELLENBERG, 1974), e a interpretação foi feita pelos métodos de médias não ponderadas (UPGMA), ligação simples e ligação completa (SNEATH e SOKAL, 1973) e expressa na forma de dendrograma, obtido através do programa NTSYS (ROHLF et al., 1971).

\section{RESULTADOS E DISCUSSÃO}

\subsection{Composição florística}

O levantamento florístico relacionou um total de 147 espécies, 98 gêneros e 50 famílias. Destas, 49 pertencem à divisão Angiospermae (Magnoliopsida) e uma à divisão Pteridophyta. Ressalta-se que 13 espécies foram identificadas somente em nível genérico, duas apenas com a identificação da família e três permaneceram sem identificação (Quadro 2).

Quadro 1 - Listagem das localidades das 25 áreas usadas para a análise de agrupamento. A formação florestal seguiu a classificação de Veloso et al. (1991)

Table 1 - List of the localities of the 25 areas used for the cluster analysis. The forest formation followed the classification of Veloso et al. (1991)

\begin{tabular}{|c|c|c|c|c|c|c|}
\hline Cód & Localidade & Formação Florestal & $\begin{array}{l}\text { Altitude } \\
(\mathrm{m})\end{array}$ & $\begin{array}{l}\text { Lat. } \\
\text { (sul) }\end{array}$ & $\begin{array}{l}\text { Long. } \\
\text { (oeste) }\end{array}$ & Autor \\
\hline $\mathrm{A}$ & Capivari, Lavras-MG & $\begin{array}{l}\text { Semidecidual Montana } \\
\text { Semidecidual Aluvial }\end{array}$ & $920-940$ & $21^{\circ} 18^{\prime}$ & $44^{\circ} 20^{\prime}$ & Souza et al., 2003 \\
\hline B & São Carlos-SP & Semidecidual Montana & 850 & $21^{\circ} 55^{\prime}$ & $47^{\circ} 48^{\prime}$ & Silva e Soares, 2003 \\
\hline $\mathrm{C}$ & $\begin{array}{l}\text { Ribeirão Cachoeira, } \\
\text { Campinas - SP }\end{array}$ & Semidecidual Montana & 650 & $22^{\circ} 50^{\prime}$ & $46^{\circ} 55^{\prime}$ & $\begin{array}{c}\text { Santos e } \\
\text { Kinoshita, } 2003\end{array}$ \\
\hline $\mathrm{D}$ & $\begin{array}{l}\text { Parque Municipal de } \\
\text { Grota Funda,Atibaia-SP }\end{array}$ & Semidecidual Montana & $900-1400$ & $23^{\circ} 10^{\prime}$ & $45^{\circ} 45^{\prime}$ & Meira-Neto et al., 1989 \\
\hline $\mathrm{E}$ & Camanducaia-MG & $\begin{array}{c}\text { Ombrófila Densa } \\
\text { Altimontana }\end{array}$ & 1900 & $22^{\circ} 42^{\prime}$ & $45^{\circ} 55^{\prime}$ & $\begin{array}{c}\text { França e } \\
\text { Stehmann, 2004 }\end{array}$ \\
\hline $\mathrm{F}$ & $\begin{array}{l}\text { Mata da Pedreira, } \\
\text { Viçosa-MG }\end{array}$ & Semidecidual Montana & 680 & $20^{\circ} 45^{\prime}$ & $42^{\circ} 55^{\prime}$ & Marangon et al., 2003 \\
\hline G & Luminárias-MG & $\begin{array}{l}\text { Semidecidual Montana } \\
\text { Semidecidual Aluvial }\end{array}$ & $880-1001$ & $21^{\circ} 29^{\prime}$ & $44^{\circ} 55^{\prime}$ & Rodrigues et al., 2003 \\
\hline $\mathrm{H}$ & Bom Sucesso-MG & $\begin{array}{l}\text { Semidecidual Montana } \\
\text { Semidecidual Aluvial }\end{array}$ & 825 & $21^{\circ} 09^{\prime}$ & $44^{\circ} 53^{\prime}$ & Carvalho et al., 1995 \\
\hline I & $\begin{array}{l}\text { Parque Estadual Serra } \\
\text { do Brigadeiro, Fazenda } \\
\text { da Neblina-MG }\end{array}$ & Ombrófila Densa Montana & 1410 & $20^{\circ} 42^{\prime}$ & $42^{\circ} 29^{\prime}$ & Ribeiro, 2003 \\
\hline
\end{tabular}

R. Árvore, Viçosa-MG, v.30, n.5, p.859-870, 2006 
Quadro 1 - Cont.

Table 1 - Cont.

\begin{tabular}{|c|c|c|c|c|c|c|}
\hline Cód & Localidade & Formação Florestal & $\begin{array}{l}\text { Altitude } \\
(\mathrm{m})\end{array}$ & $\begin{array}{l}\text { Lat. } \\
\text { (sul) }\end{array}$ & $\begin{array}{l}\text { Long. } \\
\text { (oeste) }\end{array}$ & Autor \\
\hline $\mathbf{J}$ & Conquista-MG & $\begin{array}{l}\text { Semidecidual Montana } \\
\text { Semidecidual Aluvial }\end{array}$ & 515 & $19^{\circ} 59^{\prime}$ & $47^{\circ} 36^{\prime}$ & Vilela et al., 1999 \\
\hline $\mathrm{K}$ & $\begin{array}{l}\text { Perdizes, } \\
\text { Carrancas-MG }\end{array}$ & $\begin{array}{l}\text { Semidecidual } \\
\text { Altimontana }\end{array}$ & $1440-1513$ & $21^{\circ} 36^{\prime}$ & $44^{\circ} 37^{\prime}$ & $\begin{array}{l}\text { Oliveira-Filho } \\
\text { et al., } 2004\end{array}$ \\
\hline $\mathrm{L}$ & $\begin{array}{l}\text { Núcleo de Santa Virgínia, } \\
\text { PE Serra do Mar-SP }\end{array}$ & $\begin{array}{c}\text { Ombrófila Densa } \\
\text { Montana }\end{array}$ & $870-1100$ & $23^{\circ} 24^{\prime}$ & $45^{\circ} 30^{\prime}$ & Tabarelli et al., 1994 \\
\hline M & Tripuí, Ouro Preto-MG & Semidecidual Montana & $1180-1300$ & $20^{\circ} 23^{\prime}$ & $43^{\circ} 34^{\prime}$ & Pedralli et al., 2000 \\
\hline $\mathrm{N}$ & Sapopema-PR & Semidecidual Aluvial & 780 & $24^{\circ} 01^{\prime}$ & $50^{\circ} 41^{\prime}$ & Silva et al., 1995 \\
\hline $\mathrm{O}$ & Itutinga-MG & Semidecidual Aluvial & 917 & $21^{\circ} 21^{\prime}$ & $44^{\circ} 37^{\prime}$ & Vilela et al., 1995 \\
\hline $\mathrm{P}$ & $\begin{array}{l}\text { Serra de São José, } \\
\text { Tiradentes-MG }\end{array}$ & Semidecidual Montana & 900 & $21^{\circ} 02^{\prime}$ & $44^{\circ} 15^{\prime}$ & $\begin{array}{l}\text { Oliveira-Filho e } \\
\text { Machado, } 1993\end{array}$ \\
\hline $\mathrm{Q}$ & Itatinga-SP & cidual Mon & $565-$ & $23^{\circ} 17^{\prime}$ & $48^{\circ} 33^{\prime}$ & Ivanauskas et al., 1999 \\
\hline $\mathrm{R}$ & $\begin{array}{l}\text { Reserva Biológica } \\
\text { do Tinguá-RJ }\end{array}$ & Ombrófila Densa Montana & 1500 & $22^{\circ} 39^{\prime}$ & $43^{\circ} 34^{\prime}$ & Braz et al., 2004 \\
\hline $\mathrm{S}$ & $\begin{array}{l}\text { Parque Estadual de } \\
\text { Ibitipoca-MG }\end{array}$ & Ombrófila Densa Montana & 1450 & $21^{\circ} 42^{\prime}$ & $43^{\circ} 53^{\prime}$ & Fontes, 1997 \\
\hline $\mathrm{T}$ & $\begin{array}{l}\text { Mata da Biologia, } \\
\text { Viçosa-MG }\end{array}$ & Semidecidual Montana & 670 & $20^{\circ} 45^{\prime \prime}$ & $42^{\circ} 51^{\prime \prime}$ & Gasparini Junior, 2004 \\
\hline $\mathrm{U}$ & Serra do Brigadeiro-MG & Semidecidu & 1200 & $20^{\circ} 41^{\prime} 10^{\prime \prime}$ & $42^{\circ} 29^{\prime} 35^{\prime \prime}$ & Saporetti Junior, 2005 \\
\hline $\mathrm{V}$ & Serra do Mar-PR & $\begin{array}{c}\text { Ombrófila Densa } \\
\text { Altimontana }\end{array}$ & $1380-1610$ & $25^{\circ} 32^{\prime}$ & $48^{\circ} 54^{\prime}$ & Koehler et al., 2002 \\
\hline $\mathrm{W}$ & Serra do Brigadeiro-MG & Área de estudo & 1100 & $20^{\circ} 41^{\prime} 24^{\prime \prime}$ & $42^{\circ} 29^{\prime} 47^{\prime \prime}$ & Presente trabalho \\
\hline $\mathrm{X}$ & $\begin{array}{l}\text { Poço Bonito, } \\
\text { Lavras-MG }\end{array}$ & Semidecidual Aluvial & $950-1200$ & $21^{\circ} 19^{\prime}$ & $44^{\circ} 59^{\prime}$ & $\begin{array}{l}\text { Oliveira-Filho } \\
\text { et al., } 1994\end{array}$ \\
\hline $\mathrm{Y}$ & $\begin{array}{l}\text { Madre de Deus } \\
\text { de Minas - MG }\end{array}$ & $\begin{array}{l}\text { Semidecidual Montana } \\
\text { Semidecidual Aluvial }\end{array}$ & 50 & $21^{\circ} 29^{\prime}$ & $44^{\circ} 22^{\prime}$ & Vilela et al., 2000 \\
\hline
\end{tabular}

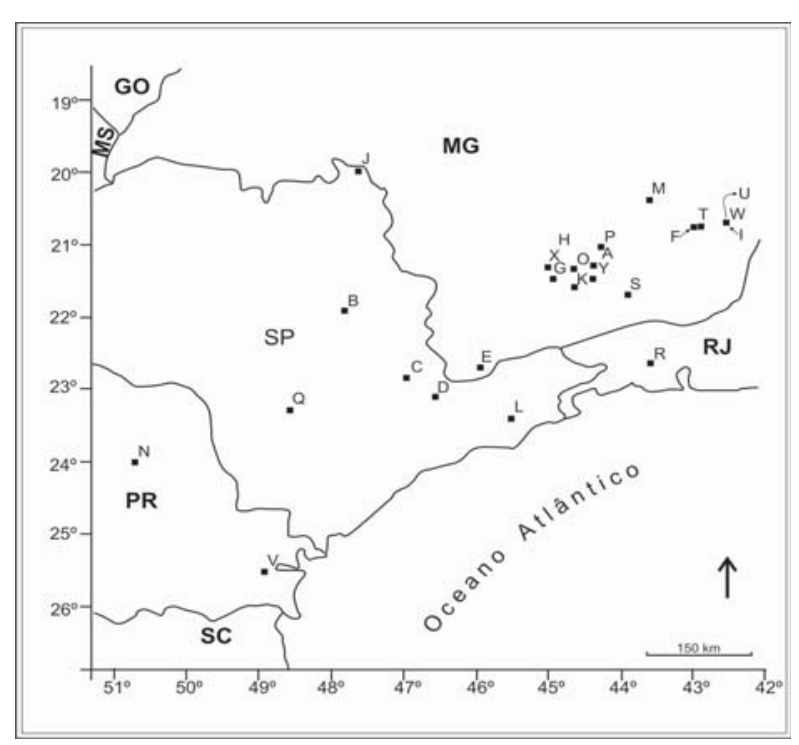

Figura 1 - Localização geográfica da área de estudo e das outras 24 áreas utilizadas para similaridade florística.

Figure 1-Geographical localization of the studied area and of the other 24 areas used for floristic similarity.
As famílias com maior número de espécies foram: Melastomataceae (14), Leguminosae (11), Myrtaceae (10), Rubiaceae (8), Annonaceae (7), Flacourtiaceae (7), Lauraceae (7) e Meliaceae (6). Essas famílias também foram as mais ricas em outros levantamentos realizados na Região Sudeste do Brasil (OLIVEIRA-FILHO et al., 1994; CARVALHO et al., 1995; VILELA et al., 1995; SILVAe SOARES, 2003; e PEDRALLI et al., 1997), onde as altitudes variavam entre 825 e $1.450 \mathrm{~m}$. Em florestas montanas de regiões neotropicais, essas famílias também aparecem com grande riqueza. Nas florestas andinas e da América Central, Melastomataceae, Rubiaceae e Lauraceae ganham destaque entre 1.500 e $3.000 \mathrm{~m}$. Annonaceae e Meliaceae aparecem como as mais ricas nas florestas pré-montanas dos Andes, situadas entre 800 e $1.500 \mathrm{~m}$ de altitude (GENTRY, 1995).

O caráter de Floresta Montana da área de estudo foi salientado pela ocorrência das espécies indicadoras de altitude Bathysa meridionalis, Lamanonia ternata e Symplocos celastrinea (MEIRA-NETO et al., 1989; OLIVEIRA-FILHO e FONTES, 2000). A ligação florística

R. Árvore, Viçosa-MG, v.30, n.5, p.859-870, 2006 
da área com outros fragmentos da Zona da Mata mineira é feita através das espécies Alchornea triplinervia, Allophylus edulis, Allophylus sericeus, Amaioua guianensis, Anadenanthera colubrina, Apuleia leiocarpa, Cariniana estrellensis, Casearia arborea, Casearia decandra, Casearia sylvestris, Casearia

Quadro 2 - Espécies e famílias amostradas na propriedade da Pousada Serra D’Água, município de Araponga, MG

Table 2 - Sampled species and families in the area belonging to Pousada Serra D'Água, Araponga, $M G$

\begin{tabular}{|c|}
\hline Famílias/Espécies \\
\hline Anacardiaceae \\
\hline Tapirira guianensis Aubl. \\
\hline Tapirira marchandii Engl. \\
\hline Annonaceae \\
\hline Annona cacans Warm. \\
\hline Guatteria mexiae R.E. Fr. \\
\hline Guatteria sellowiana Schltdl. \\
\hline Guatteria villosissima St.Hilaire \\
\hline Rollinia laurifolia Schltdl. \\
\hline Rollinia sericea (R.E. Fr.) R.E. Fr. \\
\hline Rollinia sylvatica (A. St.-Hil.) Martius \\
\hline Apocynaceae \\
\hline \multirow{2}{*}{$\begin{array}{l}\text { Aspidosperma polyneuron Müll. Arg. } \\
\text { Himatanthus phagedaenicus (Mart.) Woodson }\end{array}$} \\
\hline \\
\hline Tabernaemontana affinis Müll. Arg. \\
\hline Aquifoliaceae \\
\hline Ilex brevicuspis Reissek \\
\hline Ilex dumosa Reissek \\
\hline Araliaceae \\
\hline Didymopanax micranthus Marchal \\
\hline Asteraceae \\
\hline Vernonia diffusa Less. \\
\hline Bignoniaceae \\
\hline \multirow{3}{*}{$\begin{array}{l}\text { Cybistax antisyphilitica (Mart.) Mart. ex A. DC. } \\
\text { Tabebuia chrysotricha (Mart. ex A. DC.) Standl. } \\
\text { Bombacaceae }\end{array}$} \\
\hline \\
\hline \\
\hline Chorisia speciosa A. St.-Hil. \\
\hline Eriotheca macrophylla (K. Schum.) A. Robyns \\
\hline Pseudobombax grandiflorum (Cav.) A. Robyns \\
\hline Caricaceae \\
\hline Jacaratia spinosa (Aubl.) A. DC. \\
\hline Cecropiaceae \\
\hline Cecropia glaziovi Snethlage \\
\hline Cecropia hololeuca Miq. \\
\hline Coussapoa microcarpa (Schott) Rizzini \\
\hline Celastraceae \\
\hline Maytenus robusta Reissek \\
\hline Chrysobalanaceae \\
\hline Couepia venosa Prance \\
\hline Licania spicata Hook. f. \\
\hline Clusiaceae \\
\hline Kielmeyera albopunctata Saddi \\
\hline Garcinia gardneriana (Planch. \& Triana) Zappi \\
\hline Tovomitopsis saldanhae Engl. \\
\hline Vismia martiana Reichardt \\
\hline
\end{tabular}

ulmifolia, Cassia ferruginea, Endlicheria paniculata, Guatteria villosissima, Himatanthus phagedaenicus, Inga cylindrica, Machaerium brasiliense, Ocotea odorifera, Psychotria sessilis, Rollinia sylvatica, Sorocea bonplandii, Tapirira guianensis e Vernonia diffusa, que são as de maior ocorrência na região (SILVA et al., 2003).

Quadro 2-Cont.

Table 2 - Cont.

Famílias/Espécies

Combretaceae

Terminalia hylobates Eichler

Cunoniaceae

Lamanonia ternata Vell.

Cyatheaceae

Alsophila setosa Kaulf.

Cyathea corcovadensis (Raddi) Domin

Cyathea delgadii Sternb.

Cyathea phalerata Mart

Elaeocarpaceae

Sloanea monosperma Vell.

Euphorbiaceae

Alchornea triplinervia (Spreng.) Müll. Arg.

Hyeronyma alchorneoides Allemão

Pera glabrata (Schott) Poepp. ex Baill.

Sapium glandulatum (Vell.) Pax

Flacourtiaceae

Banara vellozii Gardn.

Casearia arborea (Rich.) Urb.

Casearia decandra Jacq.

Casearia gossypiosperma Briq.

Casearia obliqua Spreng.

Casearia sylvestris $\mathrm{Sw}$.

Casearia ulmifolia Vahl ex Vent.

Lauraceae

Cryptocarya moschata Nees \& C. Mart.

Endlicheria paniculata (Spreng.) J.F. Macbr.

Nectandra oppositifolia Nees \& Mart.

Ocotea corymbosa (Meisn.) Mez

Ocotea dispersa (Nees) Mez

Ocotea odorifera (Vellozo) Rohwer

Ocotea sp.

Lecythidaceae

Cariniana estrellensis (Raddi) Kuntze

Leguminosae Caesalpinoideae

Apuleia leiocarpa (Vogel) J.F. Macbr

Cassia ferruginea (Schrader) Schrader ex DC.

Leguminosae Mimosoideae

Anadenanthera colubrina (Vell.) Brenan

Inga cylindrica (Vell.) Mart.

Inga marginata Willd.

Inga sessilis (Vell.) Mart.

Inga vera Willd.

Pseudopiptadenia contorta (DC.) G.P. Lewis \& M.P. Lima Lonchocarpus muehlbergianus Hassl.

Continua ...

Continued... 
Quadro 2 - Cont. Table 2 - Cont

Famílias/Espécies

Leguminosae Papilonoideae

Machaerium brasiliense Vogel

Swartzia pilulifera Benth.

Lythraceae

Lafoensia glyptocarpa Koehne

Lafoensia sp.

Malpighiaceae

Byrsonima lancifolia A. Juss.

Melastomataceae

Melastomataceae sp1

Melastomataceae sp2

Meriania sp.

Miconia budlejoides Triana

Miconia cinnamomifolia (DC.) Naudin

Miconia eichlerii Cogn.

Miconia latecrenata Triana

Miconia theaezans (Bonpl.) Cogn.

Miconia tristis Spring

Mouriri chamissoana Cogn.

Tibouchina granulosa (Desr.) Cogn.

Tibouchina sp1

Tibouchina sp2

Tibouchina sp3

Meliaceae

Cabralea canjerana (Vell.) Mart.

Cedrela fissilis Vell.

Trichilia catigua A. Juss.

Trichilia emarginata (Turcz.) C. DC.

Trichilia lepidota Mart.

Monimiaceae

Mollinedia schottiana (Spreng.) Perkins

Siparuna reginae (Tul.) A. DC.

Moraceae

Acanthinophyllum ilicifolia (Spreng.) W.C. Burger

Ficus mexiae Standl.

Sorocea bonplandii (Baill.) W.C. Burger, Lanj. \& Wess. Boer Sorocea guilleminiana Gaudich.

Myristicaceae

Virola oleifera (Schott) A.C. Sm.

Myrsinaceae

Myrsine ferruginea (Ruiz \& Pav.) Spreng.

Myrsine umbellata Mart

Myrtaceae

Calyptranthes clusiaefolia (Miq.) O. Berg

Campomanesia guaviroba (DC.) Kiaersk.

Campomanesia guazumifolia (Cambess.) O. Berg

Eugenia eurysepala Kiaersk.

Eugenia neoverrucosa Sobral

Eugenia sp.

Myrcia fallax (Rich.) DC.

Psidium cupreum O. Berg

Siphoneugenia sp.

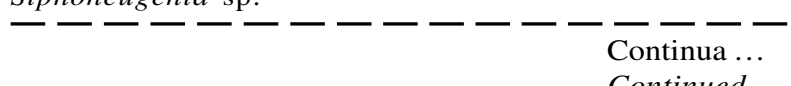

Quadro 2 - Cont

Table 2-Cont.

Famílias/Espécies

Nyctaginaceae

Guapira opposita (Vell.) Reitz

Olacaceae

Heisteria silvianii Schwacke

Opiliaceae

Agonandra brasiliensis Miers ex Benth. \& Hook. f.

Agonandra sp.

Piperaceae

Piper sp.

Proteaceae

Euplassa sp.

Roupala brasiliensis Klotzsch

Rhamnaceae

Rhamnidium elaeocarpum Reissek

Rosaceae

Prunus sellowii Koehne

Rubiaceae

Amaioua guianensis Aubl.

Bathysa cuspidata (St. Hil.) Hook. f.

Bathysa meridionalis L.B. Sm. \& Downs

Coussarea sp.

Psychotria capitata Ruiz \& Pav.

Psychotria nuda (Cham. \& Schltd1.) Wawra

Psychotria sessilis Vell.

Randia armata (Sw.) DC.

Rutaceae

Dictyoloma incanescens DC.

Sabiaceae

Meliosma itatiaiae Urb.

Sapindaceae

Allophylus edulis (A. St.-Hil., Cambess. \& A. Juss.) Radlk. Allophylus sericeus Randlk

Cupania vernalis Cambess.

Matayba elaeagnoides Radlk.

Sapotaceae

Chrysophyllum marginatum (Hook. \& Arn.) Radlk.

Solanaceae

Cestrum schlechtendalii G. Don

Solanum cinnamomeum Sendtn.

Solanum leucodendron Sendtn.

Styracaceae

Styrax sp.

Symplocaceae

Symplocos celastrinea Mart. ex Miq.

Theaceae

Gordonia semiserrata (Nees) Spreng.

Verbenaceae

Aloysia virgata (Ruiz \& Pav.) Juss.

Vochysiaceae

Callisthene minor Mart.

Qualea gestasiana A. St.-Hil.

Vochysia magnifica Warm.

R. Árvore, Viçosa-MG, v.30, n.5, p.859-870, 2006 


\subsection{Análise de agrupamento}

A composição florística de uma área pode ser influenciada por diversos fatores, como altitude, latitude, face de exposição das encostas e distância do oceano Atlântico, sendo esse último o fator que condiciona o caráter ombrófilo ou estacional, pois a estacionalidade climática é bem marcada nas áreas mais interioranas do continente (MEIRA-NETO e MARTINS, 2002; FONTES, 1997).

A formação florestal ocorrente na Serra do Brigadeiro foi classificada por Engevix (1995) como Estacional Semidecidual. Ribeiro (2003), trabalhando na região, contestou essa classificação quando observou, através da análise de agrupamento, a similaridade florística da sua área de estudo com outras Florestas Ombrófilas de Minas Gerais, aliada ao fato de não ter observado a caducifolia durante os meses secos.

O resultado da análise de agrupamento entre as áreas (Quadro 1) está contido nos dendrogramas (Figura 2), gerado a partir da matriz de similaridade (Quadro 3). Com a utilização dos três métodos, foi possível verificar que as ligações foram consistentes, ou seja, repetiramse em mais de um método. Os valores discutidos são referentes ao resultado da UPGMA.

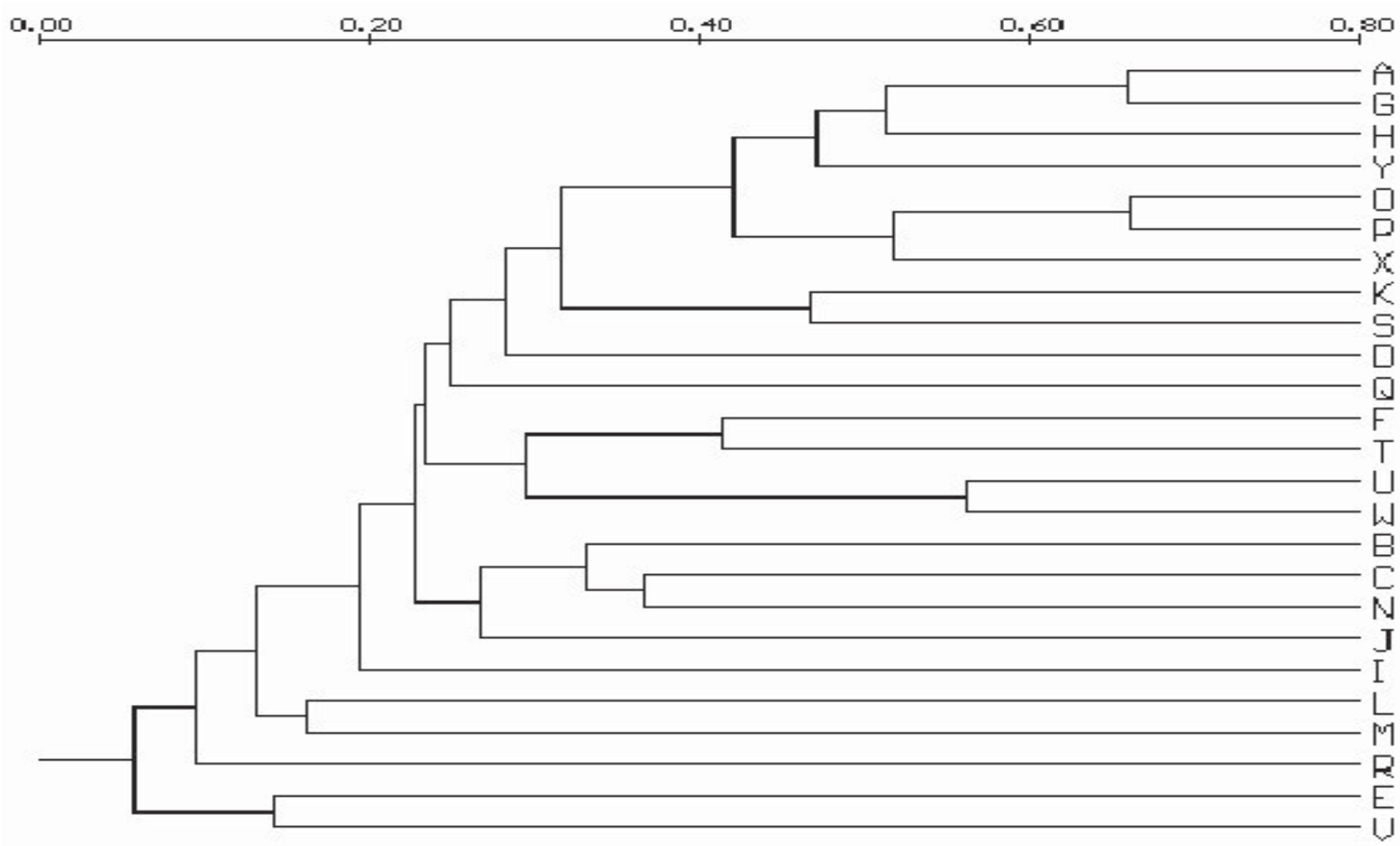

Figura 2 - Dendrograma de similaridade florística obtido pelos métodos de médias não ponderadas (UPGMA) com base no índice de SØrensen, entre 25 áreas do Sudeste e Sul do Brasil. A - Capivari, B - São Carlos, C - Ribeirão Cachoeira, D - Atibaia, E - Camanducaia, F - Mata da Pedreira, G - Luminárias, H - Bom Sucesso, I - Fazenda da Neblina, J - Conquista, K - Carrancas, L - Núcleo Santa Virgínia, M - Tripuí, N - Sapopema, O - Itutinga, P - Tiradentes, Q - Itatinga, R - Tinguá, S - Ibitipoca, T - Mata da Biologia, U - Serra do Brigadeiro V - Serra do Mar, W - Serra do Brigadeiro (este trabalho), X - Poço Bonito e Y - Madre de Deus de Minas.

Figure 2 - Dendrogram of floristic similarity obtained by the Unweighted Pair Group Method with Arithmetic mean (UPGMA) based on the SØrensen index, among 25 areas of the Southeastern and Southern Brazil. A - Capivari, B - São Carlos, C-Ribeirão Cachoeira, D-Atibaia, E-Camanducaia, $F$ - Mata da Pedreira, $G$ - Luminárias, $H$ Bom Sucesso, I - Fazenda da Neblina, J-Conquista, K-Carrancas, L-Núcleo Santa Virgínia, M - Tripuí, $N$-Sapopema, $O$-Itutinga, $P$ - Tiradentes, $Q$-Itatinga, $R$ - Tinguá, $S$ - Ibitipoca, $T$ - Mata da Biologia, $U$ - Serra do Brigadeiro V-Serra do Mar, W-Serra do Brigadeiro (this work), X-Poço Bonito, Y-Madre de Deus de Minas. 


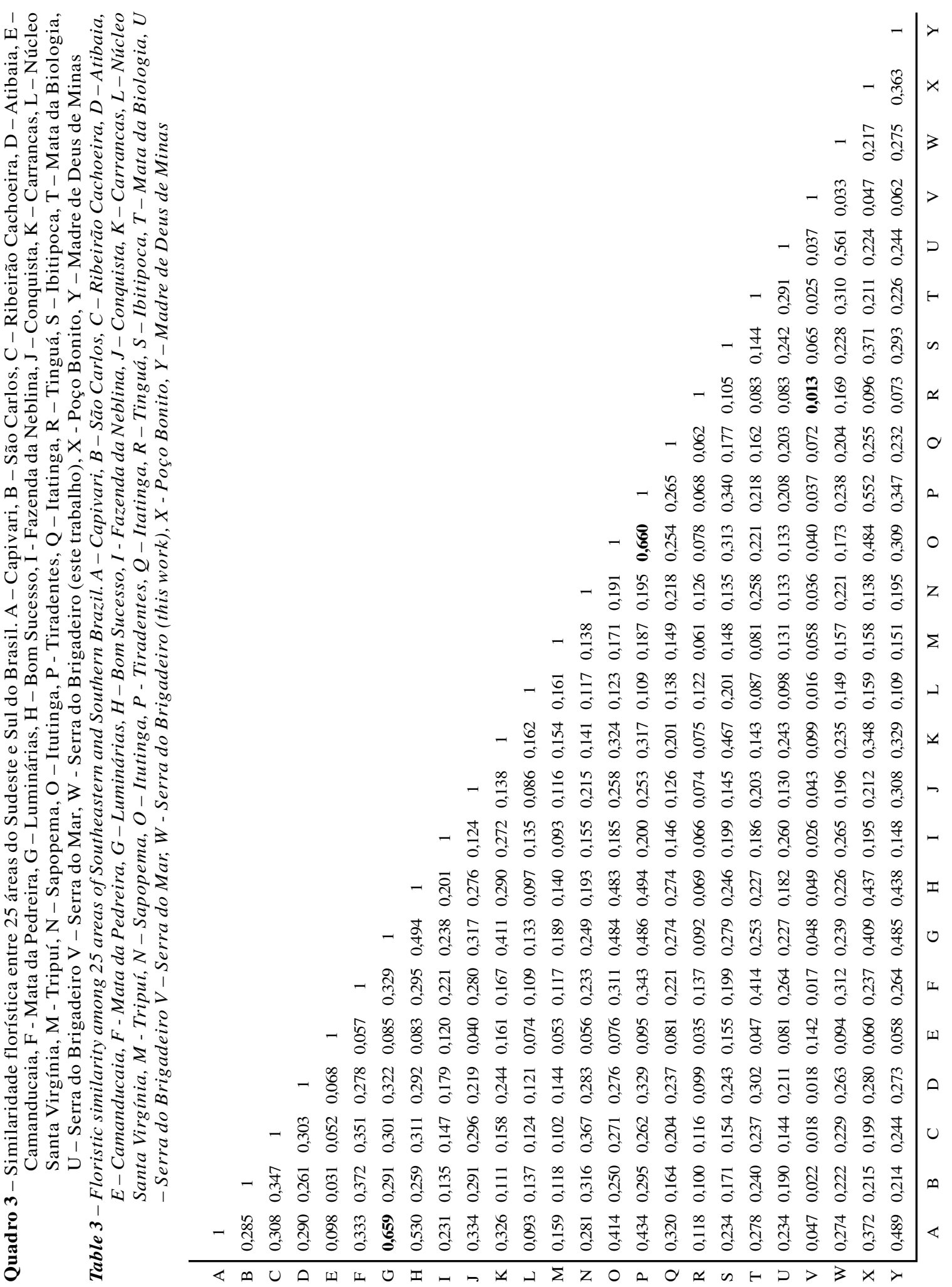


A área do presente estudo (W) faz parte do grupo formado por 18 Florestas Estacionais Semideciduais e uma Ombrófila Densa. A maior similaridade com índice de 0,56 ocorreu com um fragmento da Serra do Brigadeiro (U) mais próximo latitudinalmente e com diferença de apenas $100 \mathrm{~m}$ de altitude. Essas duas foram ligadas com índice de 0,31 à Mata da Pedreira $(F)$ e Mata da Biologia (T), também próximas geograficamente da área de estudo. Tais áreas apresentam características edáficas semelhantes, o mesmo tipo de solo (Latossolo VermelhoAmarelo), pluviosidade anual variando 1.200 a 1.300 mm e clima do tipo $\mathrm{Cw}_{\mathrm{b}}$ As espécies comuns a essas áreas foram: Allophylus edulis, Amaioua guianensis, Annona cacans, Apuleia leiocarpa, Casearia arborea, Casearia decandra, Cecropia hololeuca, Endlicheria paniculata, Guapira opposita, Matayba elaeagnoides, Maytenus robusta, Myrcia fallax, Ocotea corymbosa, Ocotea odorifera, Prunus sellowii, Psychotria sessilis e Sapium glandulatum. A maior dissimilaridade florística da área de estudo se deu com a Serra do Mar (V), por ser a área mais distante geograficamente, além de clima, precipitação e altitude diferentes.

As áreas A (Capivari), G (Luminárias), H (Bom Sucesso), Y (Madre de Deus de Minas), O (Itutinga), $\mathrm{P}$ (Tiradentes) e X (Poço Bonito), todas localizadas no Campo das Vertentes do Estado de Minas Gerais e fazendo parte da Bacia do Rio Grande, ficaram unidas com índice de 0,3 . Tais áreas foram classificadas como Floresta Estacional Semidecidual e, ou, Floresta Estacional Semidecidual Aluvial. As espécies comuns a todos as áreas são: Amaioua guianensis, Cabralea canjerana, Calophyllum brasiliense, Calyptranthes clusiaefolia, Casearia sylvestris, Croton floribundus, Crypytocaria aschersoniana, Dendropanax cuneatus, Faramea cyanea, Guatteria nigrescens, Ixora warmingii, Macherium nyictitans, Macherium villosum, Myrsine umbellata, Ocotea corymbosa, Qualea multiflora, Tapirira guianensis, Vismia brasiliensis, Xylopia brasiliensis e Zanthoxylum rhoifolium.

As maiores similaridades desse grupo foram representadas pela ligação entre Capivari (A) e Luminárias (G), Itutinga $(\mathrm{O})$ e Tiradentes $(\mathrm{P})$. Essas áreas se encontram em latitudes e altitudes próximas. Entretanto, os tipos de solos encontrados em Capivari (A) e Luminárias $(\mathrm{G})$ foram argissolos, cambissolos e neossolos flúvicos, enquanto em Itutinga $(\mathrm{O})$ e Tiradentes $(\mathrm{P})$ o solo foi classificado com o cambissolo álico.
A área I (Fazenda da Neblina), também localizada na Serra do Brigadeiro, a $1.400 \mathrm{~m}$ de altitude, apresentou ligação de 0,27 com a área do presente estudo. Nesse caso, provavelmente a diferença de altitude foi o que contribuiu para uma menor similaridade florística. Essa área não formou grupo, sendo que a similaridade estabelecida com as Ombrófilas (Santa Virgínia, Tinguá, Camanducaia e Serra do Mar) foi de 0,18, e com o grupo das Florestas Semideciduais a ligação mostrou-se maior, com índice de 0,22. Tal fato pode ser explicado pela área estar em latitude mais próxima das Semideciduais do que das Florestas Ombrófilas analisadas.

As Florestas Ombrófilas não formaram grupos, mas a influência da altitude e latitude pode ser observada nas ligações entre elas. Entre a Serra do Mar (V) e Camanducaia (E), a ligação foi em índice de 0,14 , e as duas apresentaram similaridade de 0,07 com Tinguá $(\mathrm{R})$.

Houve dois casos em que a ligação entre Florestas Semideciduais e Florestas Ombrófilas foi maior do que entre áreas da mesma formação. A similaridade estabelecida entre Carrancas (K) e Ibitipoca (S) foi de 0,47 . O outro caso foi entre Santa Virgínia (L) e Tripuí (M), com uma similaridade de 0,16.

As áreas da Serra do Brigadeiro (I) e Ibitipoca (S) consideradas como Ombrófilas, obtiveram maior semelhança com as Florestas Estacionais Semidecíduas, provavelmente pelo caráter da latitude. A abrangência dessas áreas não ultrapassa $21^{\circ} \mathrm{S}$, enquanto todas as outras áreas de Floresta Ombrófila, incluídas neste trabalho, estão localizadas acima de $22^{\circ}$ de latitude. Aumentando o número de levantamentos de Floresta Ombrófila na mesma latitude ou latitudes próximas das duas áreas, talvez a ligação com essa formação seria maior do que com as Semideciduais. Atentando para o fato de que a altitude também deve ser considera quando se faz comparação entre áreas, pois, como já foi visto, é determinante na composição florística, sendo que muitas espécies e famílias se destacam a certas faixas altitudinais.

Portanto, levando em consideração a altitude, a latitude, o clima e principalmente a composição florística da área de estudo, que mostrou alta similaridade com outras florestas de altitude das Regiões Sudeste e Sul, ela pode ser classificada como Floresta Estacional Semidecidual Montana, segundo a classificação de Veloso et al. (1991).

R. Árvore, Viçosa-MG, v.30, n.5, p.859-870, 2006 


\section{CONCLUSÕES}

A composição florística do fragmento estudado na Serra do Brigadeiro apresentou padrão florístico semelhante ao das Florestas Montanas do Sudeste do Brasil, onde as famílias Melastomataceae, Rubiaceae e Lauraceae se destacam nas altitudes mais elevadas. Além disso, espécies indicadoras de altitude também foram registradas na amostragem.

Os resultados da análise de agrupamento revelaram que os aspectos de proximidade geográfica e altitude são os principais responsáveis pela similaridade florística de muitas áreas. A vegetação da área de estudo pode ser classificada como Floresta Estacional Semidecidual Montana, pelo fato de a sua composição florística mostrar alta similaridade com outras áreas dessa mesma tipologia.

\section{REFERÊNCIAS BIBLIOGRÁFICAS}

BRAZ, D. M.; MOURA, M. V. L. P.; ROSA, M. M. T. Chave de identificação para as espécies de dicotiledôneas arbóreas da Reserva Biológica de Tinguá, RJ, com base em caracteres vegetativos. Acta Botanica Brasilica, v. 18, n. 2, p. 225-240, 2004.

CAIAFA, A. N. Composição florística e estrutura da vegetação sobre afloramento rochoso no Parque Estadual da Serra do Brigadeiro, MG. 2002. 55 f. Dissertação (Mestrado em Botânica) Universidade Federal de Viçosa, Viçosa, MG, 2002.

CAPOBIANCO, J. P. R. Mata Atlântica. Conceitos, abrangência e área original. In: SCHÄFFER, W. B.; PROCHNOW, M. A Mata Atlântica e você: como preservar, recuperar e se beneficiar da ameaçada floresta brasileira. Brasília: APREMAVI, 2002.156 p.

CARVALHO, D.A. et al. Estrutura fitossociológica de mata ripária do Alto Rio Grande (Bom Sucesso, estado de Minas Gerais). Revista Brasileira de Botânica, v. 18, n. 1, p. 39-49, 1995.

COTTAM, G.; CURTIS, J. T. The use of distance measures in phytossociological sampling. Ecology, n. 3, v. 37, p. 451-460, 1956.

COUTO, E. A.; DIETZ, J. M. Sugestões para a criação do Parque Nacional da Serra do Brigadeiro. Viçosa, MG: Universidade Federal de Viçosa, 1980.

R. Árvore, Viçosa-MG, v.30, n.5, p.859-870, 2006
CRONQUIST, A. The evolution and classification of flowering plants. New York: New York Botanical Garden, 1988. 555 p.

EMPRESA BRASILEIRA DE PESQUISA AGROPECUÁRIA - EMBRAPA. Centro de Pesquisa de Solos. Sistema brasileiro de classificação de solos. Rio de Janeiro: 1999.

ENGEVIX. Caracterização do meio físico da área autorizada para a criação do Parque Estadual da Serra do Brigadeiro - Relatório técnico final dos estudos - 8296 - RG-H4-003/94, “VER. 1". IEF/BIRD/PRÓ-FLORESTA/ SEPLAN, 1995. $34 \mathrm{p}$.

FERNANDES, I. Taxonomia e fitogeografia de Cyatheaceae e Dicksoniaceae nas Regióes Sul e Sudeste do Brasil. 1997. 435 f. Tese (Doutorado em Botânica). Universidade de São Paulo, São Paulo, 1997.

FOnTES, M. A. L. Análise da composição florística das florestas nebulares do Parque Estadual do Ibitipoca, Minas Gerais. 1997. 50 f. Dissertação (Mestrado em Engenharia Florestal) - Universidade Federal de Lavras, Lavras, 1997.

FRANÇA, G. S.; STEHMANN, J. R. Composição florística e estrutura do componente arbóreo de uma floresta altimontana no município de Camanducaia, Minas Gerais, Brasil. Revista Brasileira de Botânica, v. 27, n. 1, p. 19-30, 2004.

GASPARINI JUNIOR, A. J. Estrutura e dinâmica de um fragmento de floresta estacional semidecidual no campus da Universidade Federal de Viçosa Viçosa (MG). 2004. 68 f. Dissertação (Mestrado em Botânica) - Universidade Federal de Viçosa, Viçosa, MG, 2004.

GENTRY, A. H. Patterns of diversity and floristic composition in neotropical montane forests. In: CHURCHILL, S.P. et al. (Eds.). Biodiversity and conservation of neotropical montane forests. New York: The New York Botanical Garden, 1995. p. 103-126. 
IVANAUSKAS, N. M.; RODRIGUES, R. R.; NAVE,A. G. Fitossociologia de um trecho de Floresta Estacional Semidecidual em Itatinga, São Paulo, Brasil. Scientia Forestalis, n. 56, p. 83-99, 1999.

JOLY, A. B. Botânica: introdução à taxonomia vegetal. 12. ed. São Paulo: Companhia Editora Nacional, 1976. 634 p.

KOEHLER, A.; GALVÃO, F.; LONGHI, S. J. Floresta ombrófila densa altomontana: aspectos florísticos e estruturais de diferentes trechos na Serra do Mar, PR. Ciência Florestal, v. 12, n. 2, p. 27-39, 2002.

MARANGON, L. C.; SOARES, J. J.; FELICIANO, A. L. P. Florística arbórea da Mata da Pedreira, município de Viçosa, Minas Gerais. Revista Árvore, v. 27, n. 2, p. 207-215, 2003.

MEIRA-NETO, J. A. A. et al. Composição florística da floresta semidecídua de altitude do Parque Municipal da Grota Funda (Atibaia, Estado de São Paulo). Acta Botanica Brasilica, v. 2, n. 3, p. 51-74, 1989.

MEIRA-NETO, J. A. A.; MARTINS, F. R. Composição florística de uma floresta estacional semidecidual montana no município de Viçosa - MG. Revista Árvore, v. 26, n. 4, p. 437-446, 2002.

\section{MISSOURI BOTANICAL GARDEN. MOBOT. (on} line). Disponível na internet via: http:// www.mobot.org/W3T/search/vasthtml (acesso em dezembro de 2004).

MUELLER-DOMBOIS, D.; ELLENBERG, H. Aims and methods of vegetation ecology. New York: Jonh Willey \& Sons, 1974. 547p.

OLIVEIRA-FILHO, A. T.; MACHADO, J. N. M. Composição florística de uma floresta semidecídua montana, na Serra de São José, Tiradentes, Minas Gerais. Acta Botanica Brasilica, v. 7, n. 2, p. 71-88, 1993.

OLIVEIRA-FILHO, A. T. et al. Estrutura fitossociológica e variáveis ambientais em um trecho de mata ciliar do córrego dos Vilas Boas, Reserva Biológica do Poço Bonito, Lavras (MG). Revista Brasileira de Botânica v. 17, n. 1, p. 67-85, 1994.
OLIVEIRA-FILHO, A. T.; FONTES, M. A. L. Patterns of floristic differentiation among atlantic forests in southeastern Brazil and the influence of climate. Biotropica, v. 32, n. 4b, p. 793-810, 2000.

OLIVEIRA-FILHO, A. T. et al. Variações estruturais do comportamento arbóreo de uma floresta semidecídua alto-montana na chapada das Perdizes, Carrancas, MG. Revista Brasileira de Botânica, v. 27, n. 2, p. 291-309, 2004.

PEDRALLI, G. et al. Levantamento florístico na estação Ecológica do Tripuí, Ouro Preto, MG. Acta Botanica Brasilica, v. 11, n. 2, p. 191-213, 1997.

PEDRALLI, G. et al. Florística e fitossociologia da Estação Ecológica do Tripuí, Ouro Preto, MG.

Ciência Agrotécnica, v. 24, p. 103-136, 2000.

RIBEIRO, C. A. N. Florística e

fitossociologia de um trecho de

floresta atlântica de altitude na fazenda da Neblina, Parque Estadual da Serra do Brigadeiro, Minas

Gerais. 2003. 52 f. Dissertação (Mestrado em Botânica) - Universidade Federal de Viçosa, Viçosa, MG, 2003.

RODRIGUES, L. A. et al. Florística e estrutura da comunidade arbórea de um fragmento florestal em Luminárias, MG. Acta Botanica Brasilica, v. 17, n. 1, p. $71-87,2003$.

ROHLF, F. J.; AUGH, J. K.; KIRK, D. NTSYS Numerical taxonomy system of multivariate statistical programs. New York: Tech. Rep. State University of New York at Stony Brook, 1971.

ROYAL BOTANICAL GARDENS - Kew. Index Kewensis on compact disc - Manual. Oxford: Oxford University Press, 1993.67 p.

SANTOS, K.; KINOSHITA L. S. Flora arbustivoarbórea do fragmento de floresta estacional semidecidual do Ribeirão Cachoeira, município de Campinas, SP Acta Botanica Brasilica, v. 17, n. 3 , p. 325-341, 2003.

R. Árvore, Viçosa-MG, v.30, n.5, p.859-870, 2006 
SAPORETTI JUNIOR, A. W. Composição florística e estrutura do componente arbóreo em um remanescente de Floresta Atlântica Montana, Araponga, MG. 2005. 84 f. Dissertação (Mestrado em Botânica) - Universidade Federal de Viçosa, Viçosa, MG, 2005.

SILVA, A. F. et al. Composição florística e grupos ecológicos de um trecho de floresta semidecídua submontana da fazenda São Geraldo, Viçosa - MG. Revista Árvore, v. 27, n. 3, p. 311-319, 2003.

SILVA, F. C. et al. Composição florística e fitossociologia do componente arbóreo das florestas ciliares da Bacia do Rio Tibagi. 3. Fazenda Bom Sucesso, Município de Sapopema, PR. Acta Botanica Brasilica, v. 9, n. 1, p. 289-302, 1995.

SILVA, L. A.; SOARES, J. J. Composição florística de um fragmento de floresta estacional semidecídua no município de São Carlos-SP. Revista Árvore, v. 27, n. 5, p. 647-656, 2003.

SNEATH, P. H.; SOKAL, R. R. Numerical taxonomy. San Francisco: W. H. Freeman and Company, 1973. 573 p.

SOUZA, J. S. et al. Análise das variações florísticas e estruturais da comunidade arbórea de um fragmento de floresta semidecídua às margens do rio Capivari, Lavras-MG. Revista Árvore, v. 27, n. 2 , p. $185-206,2003$.

TABARELLI, M.; VILLANI, J. P.; MANTOVANI, W. Estudo comparativo da vegetação de dois trechos de floresta secundária no núcleo de Santa Virgínia, Parque Estadual da Serra do Mar, SP. Revista do Instituto Florestal de São Paulo, v. 6, p. 1-11, 1994.
TORRES, R. B.; MARTINS, F. R.; KINOSHITA, L. S. Climate, soil and tree flora relationships in forests in the state of São Paulo, southeastern Brasil. Revista Brasileira de Botânica, v. 20, n. 1, p. 41-49, 1997.

VALVERDE, O. Estudo regional da Zona da Mata, de Minas Gerais. Revista Brasileira de Geografia, v. 20, n. 1, p. 3-82, 1958.

VELOSO, H. P.; RANGEL-FILHO, A. L. R.; LIMA, J. C. A. Classificação da vegetação brasileira, adaptada a um sistema universal. Rio de Janeiro: IBGE, 1991.124 p.

VILELA, E. A. et al. Flora arbustivo-arbórea de um fragmento de Mata Ciliar no alto rio Grande, Itutinga, Minas Gerais. Acta Botanica Brasilica, v. 9, n. 1, p. 87-100, 1995.

VILELA. E. A.; OLIVEIRA-FILHO, A. T.; CARVALHO, D. A. Fitossociologia de Floresta Ripária do Baixo Rio Grande, Conquista - MG. Revista Árvore, v. 23, n. 4, p. 423-433, 1999.

VILELA, E. A. et al. Caracterização estrutural de floresta ripária do Alto Rio Grande, em Madre de Deus de Minas, MG. Cerne, v. 6, n. 2, p. 41-54, 2000 .

WEBSTER, G.L. The panorama of neotropical cloud forests. In: CHURCHILL, S.P. et al. (Eds.). Biodiversity and conservation of neotropical montane forests. New York: The New York Botanical Garden, 1995. p. 53-77.

Whitmore, T.C. An introduction to tropical rain forests. Oxford: Clarendon Press, 1990. 226 p. 